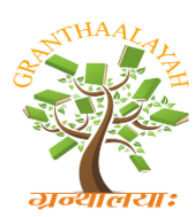

\author{
INTERNATIONAL JOURNAL OF RESEARCH - \\ GRANTHAALAYAH \\ A knowledge Repository
}

Science

\title{
QUALITY OF LIFE, SELF-CARE ACTIVITIES, AND DIABETES CONTROL AMONG SCHOOL AGE CHILDREN
}

\author{
Nabila Hassan Ali Abdella ${ }^{* 1}$ \\ ${ }^{* 1}$ Lecturers Department of Pediatrics Nursing, Faculty of Nursing, Port Said University, Egypt
}

DOI: https://doi.org/10.29121/granthaalayah.v5.i1.2017.1684

\begin{abstract}
Self-care activities and control of blood sugar levels among children with type I diabetes have a positive impact on the quality of their lives. The aim of this study was to assess the quality of life, self-care activities, and diabetes control among school age children. A descriptive design was used in the conduction of this study. Setting: The study was carried out at the Health Insurance at El-Arab El-Shamla clinic at Port Said City. A random sample of 223 children was recruited from diabetes clinic. Tools of Data Collection, two tools were used to collect the necessary data to achieve the aim of the study in six months period. The study revealed that there were statistical positive correlation between children`s quality of life, diabetes control, and their self-care activities regarding diabetes. The study was concluded that there is a clear relationship between children's high quality of life, control of diabetes and self-care activities. This study recommended that education and counseling for diabetic children are required to minimize the complications emergence and improve their quality of life.
\end{abstract}

Keywords: Quality of Life; Self-Care Activities; Diabetes Control; School Age Children.

Cite This Article: Nabila Hassan Ali Abdella. (2017). "QUALITY OF LIFE, SELF-CARE ACTIVITIES, AND DIABETES CONTROL AMONG SCHOOL AGE CHILDREN." International Journal of Research - Granthaalayah, 5(1), 1-11. https://doi.org/10.29121/granthaalayah.v5.i1.2017.1684.

\section{Introduction}

Quality of life is a broad concept that the individual's physical and mental health is affected. Thus, the quality of life reflect the impact of the disease and its treatment on the functions of the individual, where health related quality of life`s key areas of physical, emotional, school and social function (Starkey and Wade 2010 \& Sunjoo et al., 2015). There are basic self-care activities in children with type I diabetes mellitus who predicted well resulting of a healthy eating and physically active, monitoring blood sugar, compliant with medications, good skills in solving problems, coping skills and health activities to reduce risks. These activities were positively associated with good control of blood sugar, reduce complications and improve 
quality of life of diabetic children. Orem defined self-care as the activity on the care unit and maintains their own health, disease and prevention of complications associated with the disease. It can be performed through the management and the continuation of healthy lifestyles in the dimensions of physical activity, nutrition and medicines (Sarah, 2015, Sundberg \& Zinn, 2012).

Type 1 diabetes is one of the most common chronic illnesses in childhood. It is caused by a deficiency of insulin, the lack of insulin resulting from the destruction of beta cells in the pancreas that producing insulin. It has been confirmed that children who complain of diabetes to have a significant effect on the progress and development of the disease through participating in their own care. Diabetes in children represents serious physical, mental and emotional challenges, this is of the conflict that exists between diabetes and the developmental standardized diabetes management tasks that facing child who is trying to be comfortable with the rapid maturation of the body, identification, a new role in the family, and to be accepted by their peers (Spaic, 2012, Viklund and Wikblad, 2010 \& Wodrich et al., 2011).

Diabetes control was linked to the use of routinely glycosylated hemoglobin in (HbA1c). HbA1c is still the most basic measure of glycemic control that demonstrates the percentage of sugar in the blood. Maintain blood sugar levels within the target range is the goal of controlling diabetes that have a direct positive impact on the quality of life (Bujang et al., 2013, Turchin et al., 2009 \& Valerie et al., 2009).

The aim of the study: was to assess the quality of life, self-care activities, and diabetes control among school age children

\section{Materials and Methods}

\section{Study design}

A descriptive design was used in the conduction of this study

\section{Setting}

The study was carried out at the Health Insurance at El-Arab El-shamla clinic, that clinic is established to manage children with type I diabetes mellitus in Port Said Governorate.

\section{Subjects}

All diabetic school students aged 6-12 years who attended the diabetes clinic between December 2014 and March 2015 were included in the study. Random samples of 223 diabetic children were compromise the sample, who fulfill the following criteria: The children have been diagnosed as type 1 diabetes mellitus at least six months ago. Children with other chronic and psychiatric disease were excluded.

\section{Tools of Data Collection}

Two tools were used to collect the necessary data to achieve the aim of this study; First tool: Structured Interview Sheet that includes two parts: Part I: was used to collect Personal data from the diabetic children. Part II: data about the children`s knowledge, reported self-care practices, compliance about diabetes mellitus management and diabetes control. Second tool: Diabetes 
Quality of Life Scale peds QL 4.0, five- point Likert scale of the questions ranging from 1-5 Jalaludin et al.,2010, James et al.,2015 \& Varni et al., 2006.

\section{Field of work}

The researcher fulfilled the official steps required to get the approval for carrying out the study from the manager of the clinic. The researcher met with diabetic clinic manager, and explained the purpose of the study. Explain the aim of the study to children and their parents, and informing them about their rights during the study procedure. The researcher was present all the time for any clarifications. The field work was carried out during the period between December 2014 and March 2015.

\section{Pilot Study}

A pilot study was carried out after the development of the study and before embarking on the actual study (data collection) to test the clarity and reliability of the tool and feasibility of the study. It was carried out on 23 children who were excluded from the total subject of the research work. Needed modifications were done in the form of re-phrasing of some items. The internal consistency of the tool was done, and Chronbach alpha coefficient was calculated to assess the reliability. The Peds QL 4.0 reliability Scale Score by Cronbach's Alpha as 89.

\section{Ethical considerations}

The study protocol was approved by the pertinent committees in the Faculty of Nursing, Port Said University. Permissions to carry out the study were secured from official authorities in the designated clinic. Informed consents were obtained from the children and their parents before participation in the study after being informed about their right to withdraw from the study at any time without giving any reason. The collected data were strictly confidential, and would not be disclosed for any reason, and were used only for research purposes. No harmful maneuvers were performed, and no foreseen hazards are anticipated from conducting the study.

\section{Statistical analysis}

Data were coded and transferred into specially designed formats for data entry then data were analyzed and computed. Chi-square $\left(\mathrm{x}^{2}\right)$ test was used to test the associations among the under studied qualitative variables, the statistical package for social sciences (SPSS version 16.0) was used for statistical analysis. Statistical significance was considered at p-value $<0.05$.

\section{Scoring System}

The knowledge was considered "good" if percent score was $60 \%$ or more, "fair" if percent ranged from $30 \%$ to less than $60 \%$ and "poor" if less $30 \%$. The self-care practices was considered "adequate" if percent score was $60 \%$ or more, " in adequate " if percent less than $60 \%$. The children`s compliance was considered "compliant" if percent score was $60 \%$ or more and "incompliant" if less than 60\%. Finally, the QOL was considered "high" if percent score was $60 \%$ or more, "moderate" if percent ranged from $30 \%$ to less than $60 \%$ and "low" if less $30 \%$ (Mohammed, 2012). 


\section{Results and Discussions}

Table 1: Total quality of life score and its domains for diabetic children

\begin{tabular}{|c|c|c|c|c|c|c|c|}
\hline \multirow[t]{2}{*}{ Dimensions of $Q O L$} & \multicolumn{2}{|c|}{ High } & \multicolumn{2}{|c|}{ Moderate } & \multicolumn{2}{|c|}{ Low } & \multirow[t]{2}{*}{ Mean \pm SD } \\
\hline & No & $\%$ & No & $\%$ & No & $\%$ & \\
\hline School & 70 & 31.4 & 69 & 30.9 & 84 & 37.7 & $14.28 \pm 5.19$ \\
\hline Physical & $\begin{array}{l}10 \\
5\end{array}$ & 47.1 & 42 & 18.8 & 76 & 34.1 & $19.58 \pm 6.02$ \\
\hline Social & 59 & 26.5 & 105 & 47.1 & 59 & 26.5 & $26.23 \pm 7.55$ \\
\hline Emotional & 59 & 26.5 & 52 & 23.3 & 112 & 50.2 & $34.44 \pm 11.11$ \\
\hline Total quality of life & 51 & 22.9 & 51 & 22.9 & 121 & 54.3 & $92.60 \pm 26.12$ \\
\hline
\end{tabular}

Table1. Regarding the dimensions of quality of life, the social dimension was the worst $(26.5 \%)$. While, $47.1 \%$ of studied children have "high" QOL score related to physical dimension. Finally, more than half of the children had "low" total QOL (54.3\%).

Table 2: Self-care activities and diabetes control for studied children

\begin{tabular}{|l|ll|}
\hline Items & No & $\%$ \\
\hline Self-care activities: & & \\
Blood glucose monitoring: & 128 & 57.4 \\
Done & 95 & 42.6 \\
Not done & & \\
hygienic care: & 119 & 53.4 \\
Good & 78 & 35.0 \\
Fair & 26 & 11.7 \\
Poor & & \\
perform exercise: & 147 & 65.9 \\
Perform & 76 & 34.1 \\
Not perform & & \\
Regularity of meals: & 64 & 28.7 \\
Always & 94 & 42.2 \\
Sometimes & 65 & 29.1 \\
Never & & \\
Regulate insulin dose: & 107 & 48.0 \\
Yes & 116 & 52.0 \\
No & & \\
Diabetes control: & & \\
Fasting blood sugar: & 85 \\
from 80 to less than $180 \mathrm{~mm} / \mathrm{hg}$ & 113 \\
from 180 to less than $280 \mathrm{~mm} / \mathrm{hg}$ & 25 & 38.1 \\
from 280 to 380 mm/hg & & 50.7 \\
\hline
\end{tabular}


HBA1c:

Controlled (7- less than $8 \%$ )

Uncontrolled ( $8 \%$ or more)

Occurrence of complications:

yes

No

Table 2: Shows that more than half of the children perform blood glucose monitoring, have good hygienic care, and did not regulate their insulin dose (57.4\%, $53.4 \%$, and 52\%) respectively. Regarding exercise performance it was found that more than one third $(34.1 \%)$ of the children didn't perform exercise. In relation to regularity of meals, only $28.7 \%$ maintain regularity of their meals. Finally; about two thirds of the children have uncontrolled diabetes $(61.9 \%)$ and $54.3 \%$ of them have diabetes complications.

Table 3: Correlation between the diabetic children `s quality of life and their diabetes control, knowledge, self-care practice and compliance

\begin{tabular}{|c|c|c|c|c|c|c|c|c|c|c|}
\hline \multirow[t]{3}{*}{ Items } & \multicolumn{6}{|c|}{ Quality of life } & \multicolumn{2}{|c|}{ Total } & \multirow[t]{3}{*}{$\mathrm{X}^{2}$} & \multirow{3}{*}{$\begin{array}{l}\text { p- } \\
\text { value }\end{array}$} \\
\hline & \multicolumn{2}{|c|}{\begin{tabular}{|l|} 
Low \\
$n=121$
\end{tabular}} & \multicolumn{2}{|c|}{$\begin{array}{l}\text { Moderate } \\
\mathrm{n}=\mathbf{5 1}\end{array}$} & \multicolumn{2}{|c|}{$\begin{array}{l}\text { High } \\
n=51\end{array}$} & \multirow[t]{2}{*}{ No } & \multirow[t]{2}{*}{$\%$} & & \\
\hline & No & $\%$ & No & $\%$ & No & $\%$ & & & & \\
\hline \multicolumn{11}{|c|}{ Diabetes control: } \\
\hline Uncontrolled & 93 & 76.9 & 29 & 56.9 & 28 & 54.9 & 150 & 67.3 & \multirow[t]{2}{*}{11.10} & \multirow[t]{2}{*}{.004} \\
\hline Controlled & 28 & 23.1 & 22 & 43.1 & 23 & 45.1 & 73 & 32.7 & & \\
\hline \multicolumn{11}{|l|}{ Knowledge: } \\
\hline Poor & 88 & 72.7 & 22 & 43.1 & 23 & 45.1 & 133 & 59.6 & \multirow[t]{3}{*}{19.82} & \multirow[t]{3}{*}{.001} \\
\hline Fair & 18 & 14.9 & 19 & 37.3 & 16 & 31.4 & 53 & 23.8 & & \\
\hline Good & 15 & 12.4 & 10 & 19.6 & 12 & 23.5 & 37 & 16.6 & & \\
\hline \multicolumn{11}{|c|}{ Self-care practice: } \\
\hline Adequate & 92 & 76.0 & 31 & 60.8 & 26 & 51.0 & 149 & 66.8 & \multirow[t]{2}{*}{11.24} & \multirow[t]{2}{*}{.004} \\
\hline Inadequate & 29 & 24.0 & 20 & 39.2 & 25 & 49.0 & 74 & 33.2 & & \\
\hline \multicolumn{11}{|l|}{ Compliance: } \\
\hline Compliant & 30 & 24.8 & 14 & $\begin{array}{l}27 . \\
5\end{array}$ & 20 & 39.2 & 64 & 28.7 & \multirow[t]{2}{*}{3.69} & \multirow[t]{2}{*}{.157} \\
\hline Incompliant & 91 & 75.2 & 37 & $\begin{array}{l}72 . \\
5\end{array}$ & 31 & 60.8 & 159 & 71.3 & & \\
\hline
\end{tabular}

Statistically significant $\mathrm{p}<0.05$

Regarding children's diabetes control the highest percentage of those with uncontrolled diabetes have low quality of life $(76.9 \%)$. While in relation to children's knowledge, about three quarters of them whose quality of life was low their knowledge was poor (72.7\%). Also; there were highly statistical significance association between children`s quality of life and their diabetes control, knowledge, and self-care practices about diabetes $\mathrm{p} \leq .004, .001$ and .004 respectively. 
Table 4: Correlation between the diabetic children `s quality of life and their sociodemographic

\begin{tabular}{|c|c|c|c|c|c|c|c|c|c|c|}
\hline \multirow{3}{*}{ Items } & \multicolumn{6}{|c|}{ Quality of life } & & & \multirow{3}{*}{$\mathbf{X}^{2}$} & \multirow{3}{*}{ p-value } \\
\hline & \multicolumn{2}{|c|}{$\begin{array}{l}\text { Low } \\
n=121\end{array}$} & \multicolumn{2}{|c|}{$\begin{array}{l}\text { Moderate } \\
\mathrm{n}=\mathbf{5 1}\end{array}$} & \multicolumn{2}{|c|}{$\begin{array}{l}\text { High } \\
n=51\end{array}$} & \multicolumn{2}{|c|}{ Total } & & \\
\hline & No & $\%$ & No & $\%$ & No & $\%$ & No & $\%$ & & \\
\hline \multicolumn{11}{|l|}{ Age/ years } \\
\hline 6 less than 8 & 50 & 41.3 & 9 & 17.6 & 15 & 29.4 & 74 & 33.2 & \multirow{3}{*}{13.24} & \multirow{3}{*}{.010} \\
\hline 8 less than 10 & 17 & 14.0 & 17 & 33.3 & 12 & 23.5 & 46 & 20.6 & & \\
\hline $10-12$ & 54 & 44.6 & 25 & 49.0 & 24 & 47.1 & 103 & 46.2 & & \\
\hline \multicolumn{11}{|l|}{ Gender: } \\
\hline Male & 60 & 49.6 & 28 & 54.9 & 30 & 58.8 & 118 & 52.9 & \multirow[b]{2}{*}{1.33} & \multirow[b]{2}{*}{.513} \\
\hline Female & 61 & 50.4 & 23 & 45.1 & 21 & 41.2 & 105 & 47.1 & & \\
\hline
\end{tabular}

\section{Mother education:}

\begin{tabular}{|c|c|c|c|c|c|c|c|c|c|c|}
\hline Illiterate & 37 & 30.6 & 9 & 17.6 & 11 & 21.6 & 57 & 25.6 & \multirow{7}{*}{20.63} & \multirow{7}{*}{.056} \\
\hline read and write & 10 & 8.3 & 4 & 7.8 & 5 & 9.8 & 19 & 8.5 & & \\
\hline basic education & 6 & 5.0 & 6 & 11.8 & 5 & 9.8 & 17 & 7.6 & & \\
\hline preparatory education & 16 & 13.2 & 2 & 3.9 & 0 & .0 & 18 & 8.1 & & \\
\hline secondary education & 25 & 20.7 & 13 & 25.5 & 12 & 23.5 & 50 & 22.4 & & \\
\hline University & 25 & 20.7 & 17 & 33.3 & 18 & 35.3 & 60 & 26.9 & & \\
\hline master or decorate & 2 & 1.7 & 0 & .0 & 0 & .0 & 2 & .9 & & \\
\hline \multicolumn{11}{|l|}{ Mother work: } \\
\hline Housewife & 73 & 60.3 & 31 & 60.8 & 26 & 51.0 & 130 & 58.3 & \multirow{2}{*}{1.45} & \multirow{2}{*}{.482} \\
\hline Working & 48 & 39.7 & 20 & 39.2 & 25 & 49.0 & 93 & 41.7 & & \\
\hline
\end{tabular}

Statistically significant $\mathrm{p}<0.5$

Highest percentages among children who have high quality of their lives were between the ages of 10-12 years old (47.1\%). In addition, $58.8 \%$ of studied children were males and had a high quality of life and the rest of them were girls (41.2\%). Also; there were statistical significance association between children`s quality of life in relation to their age and mother's education $\mathrm{p} \leq .010$, and .056 respectively.

Table 5: Correlation coefficient between the diabetic children 's quality of life and their diabetes control, knowledge, practice and compliance:

\begin{tabular}{|l|l|l|l|l|l|}
\hline \multicolumn{1}{|c|}{ Items } & \multicolumn{1}{|c|}{$\begin{array}{c}\text { Quality of } \\
\text { life }\end{array}$} & $\begin{array}{c}\text { Diabetes } \\
\text { control }\end{array}$ & $\begin{array}{c}\text { Knowledge } \\
\text { about } \\
\text { diabetes }\end{array}$ & $\begin{array}{c}\text { Self-care } \\
\text { activities }\end{array}$ \\
\hline Quality of life & Pearson Correlation & 1 & $.209^{* *}$ & $.229^{* *}$ & $.223^{* *}$ \\
\cline { 2 - 6 } & & & .002 & .001 & .001 \\
\hline
\end{tabular}




\begin{tabular}{|l|l|l|l|l|l|}
\hline \multirow{2}{*}{ Diabetes control } & Pearson Correlation & $.209^{* *}$ & 1 & $.219^{* *}$ & $.320^{* *}$ \\
\cline { 2 - 6 } & Sig. & .002 & & .001 & .000 \\
\hline \multirow{2}{*}{$\begin{array}{l}\text { Knowledge about } \\
\text { diabetes }\end{array}$} & Pearson Correlation & $.229^{* *}$ & $.219^{* *}$ & 1 & $.424^{* *}$ \\
\cline { 2 - 6 } Self-care activities & Sig. & .001 & .001 & & .000 \\
\cline { 2 - 6 } & Pearson Correlation & $.223^{* *}$ & $.320^{* *}$ & $.424^{* *}$ & 1 \\
\cline { 2 - 6 } & Sig. & .001 & .000 & .000 & \\
\hline $\mathrm{N}$ & 223 & 223 & 223 & 223 \\
\hline
\end{tabular}

**. Correlation is significant at the 0.01 level.

This table shows that there were statistical positive correlation between children`s quality of life, diabetes control, knowledge about diabetes, and their self-care activities.

\section{Discussion}

Quality of life (QOL) is adapted to the lives of all humans, at any time, and from their individual perspectives. Quality of life is a multidimensional phenomenon that includes several aspects of well-being (Abdul-Rasoul et al., 2013 \& Wodrich et al., 2011). In this respect, the results of the current work demonstrate that more than half of the children have "low" QOL. These results could be documented by the positive correlation between the children's quality of life and their diabetes control, knowledge about diabetes, and self-care activities.

Regarding the dimensions of quality of life in the present study, the social dimension was the worst, where more than half of the studied children have low quality of life. It could be explained by children may face typical struggles for growth and independence from parents and others, which can result in poor adherence to the diabetes regimen. In addition, many of the diabetesrelated tasks can interfere with the children's drive for peer acceptance, and peer pressure may generate strong conflicts that consider emotional problems for them. On the contrary, Duru et al., 2015, Hanberger, 2010 \& Mohammed, 2010 who studies "Impact of Health Educational Program on the Quality of Life of Adolescents with Type I Diabetes in Port Said", reported that slightly more than one fifth of the adolescents of both the study and control, groups have high emotional QOL before the program.

The findings of the present study revealed that statistical significance association between children's quality of life in relation to their age and mother`s education. From the researcher`s point of view low mother educational level leads to decrease the children`s quality of life in relation to diabetes mellitus.

Blood glucose monitoring is the backbone of diabetes management. Self-monitoring enables children with type I diabetes mellitus to cope with their treatment regimen to achieve optimal blood glucose control and allows for detection and prevention of diabetes complications, which improves their quality of life. It should be performed at least three times a day for children with type I diabetes (Chih et al., 2010 \& Valerie, 2009). The results of the present study indicated that more than half of children in the study perform blood glucose monitoring. The results could be explained by the physician's and nurse`s instructions to the children and the strict parental supervision to do test, as well as the fact that glucometers and blood strips are available through the health insurance services once children diagnosed as a diabetic. Additionally, the children 
fears from hypo and hyperglycemia so they perform the test to prevent, early detect, and treat these acute complications. These results were supported by Helgeson, et al., 2010 \& Fisher et al., 2009 who reported that almost of their diabetic children monitor their blood glucose two times per day after diabetes education and did not care with urine glucose test. In contradiction to this finding, Glazier et al., 2006 found that the majority of their studied children did not perform blood glucose analysis even after the education.

The result of the current study revealed that, about two thirds of the children have good hygienic care. This result was supported by Battista et al., $2009 \&$ Ismail, 2011 who found that all adolescents with type I diabetes had good level of hygiene.

On the other hand, the results of the present study revealed that about three quarters of the studied children were compliant regarding performing exercise, compared to less than half of them could regulate their insulin dose. Meanwhile, nearly one third of the children were never regulating their meals. These results might be interpreted by the presence of more than one person in the family affected with diabetes that may act as a motivation for compliance to exercise, regulate their insulin dose and meals, also may be attributed to the long duration of the disease. Also, lack of knowledge about the importance of regular diet and the children were dependent on fast food and need for weight control. Similar finding concerning compliance to diabetes management for children with type I diabetes mellitus were reported by Edwall et al., 2010 \& Starkey and Wade 2010 who stated in their study that children with type I diabetes can begin to assume more of the daily diabetes management tasks and achieve better compliance. Regarding diabetes control, the results of the current study revealed that about two thirds of the children their diabetes was uncontrolled. In addition, more than half of the studied children have diabetes complications.

The knowledge is considered as the cornerstone of the management of type I diabetes mellitus, its control, quality of life, and their self-care activities of these children with type I diabetes mellitus (Viklund\& Wikblad, 2010 and Turchin et al., 2009). The findings of the present study have demonstrated that three quarter of those with low quality of life have poor knowledge about diabetes with statistical significance association. it could be interpreted by the children with type I diabetes were in difficult academic stage and very busy by studying their formal or additional lessons as well as have no time to attend educational classes about diabetes. Additionally, the children did not attend any training courses about diabetes. These results were consistent with Kalyva et al., 2011 \& Olinder et al., 2010 who reported that the majority of the studied children have poor knowledge.

In examining the total practice of the children with type I diabetes in the current study, it was found that slightly more than half of the children have satisfactory practice and high quality of life with highly statistical significance association between the children`s practice and their quality of life.

Compliance is not a unitary construct; rather there are many components to it. Therefore, it is important to examine compliance across several behaviors and to look at multiple aspects of compliance. (Schilling et al., 2009 and Viklund \& Wikblad, 2009). The highest percentage of the children with low quality of life were uncompliant to diabetes treatment regimen. It could be 
explained by the children, negligence and lack of knowledge about the relationship between compliance to diabetes management and diabetes control consequently their quality of life. Also may due to inadequate instructions that given to the children with type I diabetes mellitus related to compliance. In addition to, the children were realized that the diabetes is not curable disease and their religious believes. This is supported by Lindholm et al., 2010, Patton,2010 \& Mohamed,2012 who found that children in their studies were better compliance related to diabetes management when they perceived the importance of compliance after education.

\section{Conclusions \& Recommendations}

\section{Conclusion}

Based on the findings of the current study, it is concluded that the impact of diabetes was readily apparent affecting children`s quality of life, their diabetes control and their self-care activities.

\section{Recommendations}

Education, counseling, close supervision, tremendous amount of support, and utilization of the optimum resources are required to keep children with type I diabetes mellitus away from the hospital, as well as are the key to improve their quality of life.

\section{References}

[1] Abdul-Rasoul M.AlOtaibi F.Abdulla A. Rahme Z. ·AlShawaf A. (2013): Quality of Life of Children and Adolescents with Type 1 Diabetes in Kuwait. Vol. 22, No. 4, Med Princ Pract; 22:379-384.

[2] Battista A., Hart T., Greco L. and Gloizer J.(2009):Type 1 diabetes among adolescents :reduced diabetes self-care caused by social fear and fear of hypoglycemia .Diabetes Educ; 35(13): p.465475

[3] Bujang M, Supramaniam P., Haniff J, Muninathan P, Jalaludin M, Zain F, Hua J.(2013): The Association between Self-Care Practices, HbA1c and Quality of Life for Type 1 DM in Children and Adolescents. International Medical Journal Vol. 20, No. 3, pp. 337 - 339.

[4] Chih A., Jan C., Shu S. and Lue, B. (2010): Self-efficacy affects blood sugar control among adolescents with type 1 diabetes mellitus. Journal of the Formosan Medical Association; 109(7): p. 503-510.

[5] Duru NS, Civilibal M, Elevli M.(2015): Quality of Life and Psychological Screening in Children with Type 1 Diabetes and their Mothers Endocrinol Diabetes. 2016 Feb; 124 (2):105-10.

[6] Edwall L., Danielsson E., Smide B. and Öhrn I. (2010): Interaction between patients with type 2 diabetes and diabetes nurse specialists during annual check-ups: A study using video recordings. The Internet Journal of Advanced Nursing Practice; 11 (1): p. 18-24.

[7] Fisher B., Earp J ., Maman S. and Zolotor A (2009): Cross-cultural and international adaptation of peer support for diabetes management. Fam .Pract; 10(13): p.145-154.

[8] Glazier R., Bajcar J., Kennie N., Willson K. (2006) :A systematic review of interventions to improve diabetes care in socially disadvantaged populations .Diabetes Care; 30(7) p.1675-1688.

[9] Hanberger L. (2010): Quality of care in children and adolescents with type 1 diabetes patients' and healthcare professionals' perspectives. Linköping University, Faculty of Health Science, Medical Dissertation. pp 16-17

[10] Helgeson V., Escobar O., Siminerio L. and Becker D. (2010): Relation of stressful life events to metabolic control among adolescents with diabetes: Five year longitudinal study. Health Psychology; 29(2): p.153-159. 
[11] Ismail B. (2011): Self-rated health and factors influencing responses among young Egyptian type 1 diabetes patients. BMC Public Health; 11 (216): p. 1-7.

[12] Jalaludin MY, Fuziah MZ, Hadhrami MH, Janet Y, Zanariah H, Fauzi I, Adam B, Jamaiyah H. (2010).Reliability and validity of the Malay translated version of diabetes quality of life (DQoL) questionnaire. Was accepted for presentation the 36th annual meeting of the International Society for Pediatric and Adolescent Diabetes (ISPAD), Buenos Aires, Argentina from October 27th30 th.

[13] James W, Tasha M, Jenifer R, Michael G, Francine K and Kenneth L.( 2015):The PedsQL ${ }^{\text {TM }}$ in Type 1 and Type 2 Diabetes, Reliability and validity of the Pediatric Quality of Life Inventory ${ }^{\mathrm{TM}}$ Generic Core Scales and Type 1 Diabetes Module.

[14] Kalyva E., Malakonaki E., Eiser C. and Mamoulakis D. (2011): Health-related quality of life (HRQoL) of children with type 1 diabetes mellitus (T1DM): self and parental perceptions. Pediatric Diabetes;12 (3): p. 34-40.

[15] Lindholm A., Ternulf K. and Smide B. (2010): Clarifying responsibility for self-management in adolescents with diabetes using insulin pumps - a qualitative study. J Adv Nurs; 18(2): p. 176183.

[16] Mohamed N, (2012): Impact of Health Educational Program on the Quality of Life of Adolescents with Type I Diabetes in Port Said. Doctorate Dissertation, Port Said University, Faculty of Nursing in Port Said . P. 59

[17] Olinder A., Ternulf K. and Smide B. (2010): Missed bolus doses from the perspective of adolescents using insulin pumps - "Lost focus". Pediatric Diabetes; publ.on-line, availablehttp://www.healthatoz.com/healthatoz/Atoz/ency/glycosylated_hemoglobin_test.jsp Retrieved 11/10, 2010. P.1491-1494.

[18] Patton S. (2010): Adherence to treatment in children and adolescents with type one diabetes mellitus. Diabet Med; 14(5): p. S1-4

[19] Sarah A Mills, Paul L Hofman, Yannan Jiang, Yvonne C Anderson (2015): Health-related quality of life of Taranaki children with Type 1 Diabetes. 18th December 2015, Volume 128 Number 1427

[20] Schilling L., Knafl K., Gray M., Lynn M., Murphy K., Dumser S. and Dixon J. (2009): A New Self-Report Measure of Self-Management of Type 1 Diabetes for Adolescents. Journal of Nursing Research; 58(4): p. 228-236.

[21] Spaic T. (2012): Predictors of glycemic control in children with Type 1 diabetes. A thesis submitted in partial fulfillment of the requirements for the degree of Master of Science, The University of Western Ontario London, Ontario, Canada,p 21

[22] Starkey K. and Wade T. (2010): Disordered eating in girls with type 1 diabetes: examining directions for prevention. Clinical Psychologists; 14(1): p. 2-9.

[23] Starkey K. and Wade T. (2010): Disordered eating in girls with type 1 diabetes: examining directions for prevention. Clinical Psychologists; 14(1): p. 2-9.

[24] Sundberg F, Sand P, Forsander G (2015): Health-related quality of life in preschool children with Type 1 diabetes Diabet Med. 2015 Jan;32(1):116-9.

[25] Sunjoo B.,Youngmee A.,JiEun L., Narae K., Heesook K., and Min S. ( 2015): Diabetes-Specific Quality of Life of Korean Children and Adolescents With Type 1 Diabetes.

[26] Turchin A., Matheny M., Shubina M., Scanlon J., Greenwood B. and Pendergrass M. (2009): Hypoglycemia and clinical outcomes in patients with diabetes hospitalized in the general ward. Diabetes Care;32 : p.1153-1157

[27] Valerie R., Michael G., Yang L., Dana G.and Anne P .(2009): Clinical and behavioral correlates of achieving and maintaining glycemic targets in an underserved population with type 2 diabetes. Diabetes Care; 32: p.54-56 
[28] Valerie R., Michael G., Yang L., Dana G.and Anne P .(2009): Clinical and behavioral correlates of achieving and maintaining glycemic targets in an underserved population with type 2 diabetes. Diabetes Care; 32: p.54-56

[29] Varni J., Burwinkle T., seid.(2006): : The peds QL 4.0 as a school population measure :feasibility ,reliability and validity. Qual life Res, 15ed.P.P; 203-215.

[30] Viklund G. and Wikblad K. (2010): Self-perceived health and burden of diabetes in teenagers with type 1 diabetes: psychometric properties of the Swedish measure 'check your health'. Acta Paediatr; 99(3): p.422-6.

[31] Viklund G. and Wikblad K. (2010): Self-perceived health and burden of diabetes in teenagers with type 1 diabetes: psychometric properties of the Swedish measure 'check your health'. ActaPaediatr; 99(3): p.422-6.

[32] Wodrich D., Hasan K. and Parent K. (2011): Type 1 diabetes mellitus and school: a review. Pediatric Diabetes; 12: 63-70.

[33] Wodrich D., Hasan K. and Parent K. (2011): Type 1 diabetes mellitus and school: a review. Pediatric Diabetes; 12: 63-70.

[34] Zinn K. (2012): An Exploration of Diabetes Self-Care Among Older Adolescents with Type 1 Diabetes: A Focus Group Study. Loyola University Chicago, dissertations, p.p 43-44.

*Corresponding author.

E-mail address: nagwarizk99@gmail.com 